\title{
Research and Application of Micronized Barite Drilling Fluid in HPHT Wells of the Western South China Sea
}

\author{
Han Cheng, Zhang Chao, Luo Ming, Wei Anchao, Xu Fabin \\ CNOOC Ltd. Zhanjiang, Zhanjiang, Guangdong, China

\section{Email address:} \\ hancheng3@cnooc.com.cn (Han Cheng), zhangchao1@cnooc.com.cn (Zhang Chao), luoming1@cnooc.com.cn (Luo Ming), \\ Weianchao@cnooc.com.cn (Wei Anchao),xufb@cnooc.com.cn (Xu Fabin)
}

\section{To cite this article:}

Han Cheng, Zhang Chao, Luo Ming, Wei Anchao, Xu Fabin. Research and Application of Micronized Barite Drilling Fluid in HPHT Wells of the Western South China Sea. International Journal of Oil, Gas and Coal Engineering. Vol. 4, No. 2, 2016, pp. 9-15.

doi: 10.11648/j.ogce.20160402.11

Received: February 26, 2016; Accepted: March 6, 2016; Published: March 19, 2016

\begin{abstract}
When drilling wells in high temperature and high pressure (HTHP) fields, the drilling fluid properties are of utmost importance. If the viscosity of high density drilling fluid is too low, it will lead to barite sag and poor cuttings carrying capacity. However, lost circulation will occur due to high surge pressure and Equivalent Circulating Density (ECD) caused by high viscosity. High density drilling fluid performance is largely dependent on the use of the weighting material. The contradiction between rheological properties and barite sag of API Barite High Density Drilling Fluid (HABF) is great in the condition of HTHP. This article describes a novel weighting material that has resulted in a ten-fold reduction in the particle size of API barite. With this micronized barite, the contradiction of high density drilling fluid can be solved. The rheology, sag stability and lubricity of high density drilling fluid weighted by micronized barite and API barite is investigated in the laboratory. And the mechanism of micronized barite to improve the performance of high density drilling fluid is discussed by using size distribution, surface charge, and microscopic shape method. Micronized Barite High Density Drilling fluid (HMBF) was first applied in two HTHP exploration wells with good gas show recently, which are in Western South China Sea. HMBF exhibited good rheological properties, sag stability and lubricity in the drilling process. Drilling task was successfully completed, without complicated situation.
\end{abstract}

Keywords: High Temperature and High Pressure, Micronized Barite, High-Density Drilling Fluid, Barite Sag, Weighting Material

\section{Introduction}

The formation pressure drilled in YQ Basin in Western South China Sea, is up to $104.70 \mathrm{MPa}$, and the highest temperature can reach $251.76^{\circ} \mathrm{C}$ [1]. Western South China Sea, British North Sea Rochelle Watt and the Gulf of Mexico are called the world's three major HTHP oil and gas fields [2]. For environmental reasons, water-based drilling fluid is used for HPHT drilling in Western South China Sea generally. But high temperature leads to deterioration of water-based drilling fluids rheological properties easily, and high pressure easily leads to lost circulation, blowout and other complex accidents $[3,4]$. The development of HTHP oil and gas fields in Western South China Sea is seriously influenced by complications, such as pipe sticking, lost circulation and well control problem, which often arise in the past HTHP drilling operation.

The contradiction between rheology and barite sag is one of the main difficulties in high density drilling fluid technology. The success or failure of HTHP well drilling largely depends on whether the performance of high density drilling fluid is stable, while the control of high density drilling fluid performance depends on the use of weighting materials to a large extent [5].

Gunnar explained in detail the first field applications of micronized barite in an oil-based drilling fluid. The system was used to drill two wells offshore Norway. Performance data from offset wells will be presented that show ECD and torque values were significantly lower than comparable wells and no instances of particle settlement were observed [6].

Michel reviews the application of HMBF to drill a deviated high-temperature, high-pressure (HTHP) well in the Northern 
North Sea in 2009. The HMBF was used to drill the $81 / 2$-in. section from 6354 to $7327 \mathrm{~m}$. The bottom hole static temperature was $205^{\circ} \mathrm{C}$ and maximum mud weight $2.15 \mathrm{~g} / \mathrm{cm}^{3}$ The well was successfully drilled to TD with no significant sag occurred [7].

Overseas researches show that the contradiction between barite sag and rheology of high density drilling fluid is solved very well by micronized barite. But the study of the mechanism of improving properties of high density drilling fluid weighted by micronized barite is not enough. This paper compares rheology, sag stability, and lubricity of high-density drilling fluid weighted by micronized barite and API barite, and the corresponding mechanism is discussed. The application of HMBF in two HPHT wells with good gas show in western South China Sea is introduced in detail, and to provide a reference for offshore HPHT drilling.

\section{Performance Evaluation}

\subsection{Rheology}

Polysulfonate drilling fluids (AF) and polyol drilling fluids (BF), commonly used in HTHP wells in China, are selected to study the performance of high-density drilling fluid densified with micronized barite and API barite. The two fluid formulations are given in Table 1.

Table 1. AF and BF formulation

\begin{tabular}{llll}
\hline Polysulfonate drilling fluid(AF) & & polyol drilling fluid $(\mathbf{B F})$ & Concentration $\mathbf{~ k g} / \mathbf{m}^{\mathbf{3}}$ \\
\hline Product & Concentration $\mathbf{~ k g} / \mathbf{m}^{\mathbf{3}}$ & Product & 1000 \\
\hline water & 1000 & water & 20 \\
bentonite & 20 & bentonite & 1.5 \\
sodium hydroxide & 1.5 & sodium hydroxide & 5 \\
inhibitor(KPAM) & 2.5 & Polyanionic cellulose & 5 \\
High temperature fluid loss agent(SMP-1) & 30 & salt-resisting & 5 \\
Asphalt type of fluid loss agent(SDL) & 30 & fluid loss agent & 30 \\
thinning agent(SDX) & 5 & thinning agent(SDX) & 30 \\
Sulfonated lignite & 25 & Asphalt type of fluid loss agent(SDL) & \\
\hline
\end{tabular}

Densifying AF and BF with micronized barite and API barite to $1.6 \mathrm{~g} / \mathrm{cm}^{3}, 1.8 \mathrm{~g} / \mathrm{cm}^{3}, 2.0 \mathrm{~g} / \mathrm{cm}^{3}, 2.2 \mathrm{~g} / \mathrm{cm}^{3}, 2.4 \mathrm{~g} / \mathrm{cm}^{3}$ respectively, and viscosity of the slurries are tested after aging in $150^{\circ} \mathrm{C}$ for $16 \mathrm{~h}$. Experimental results are shown in Figure 1 and Figure 2.
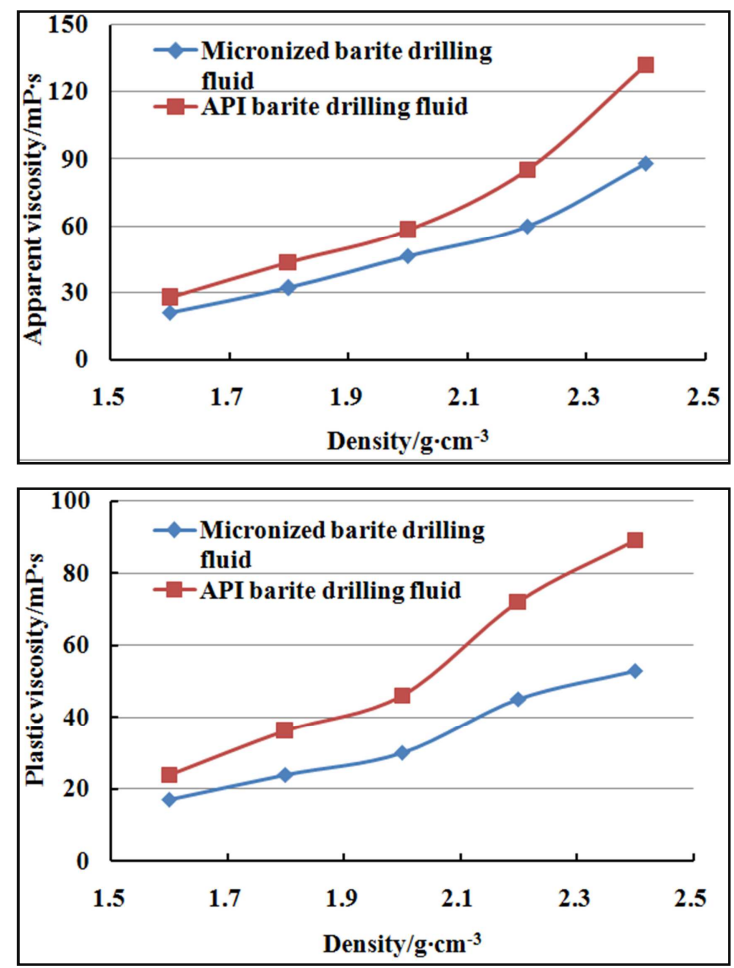

Fig. 1. The viscosity changes with the density of AF weighted with micronized barite and API barite.
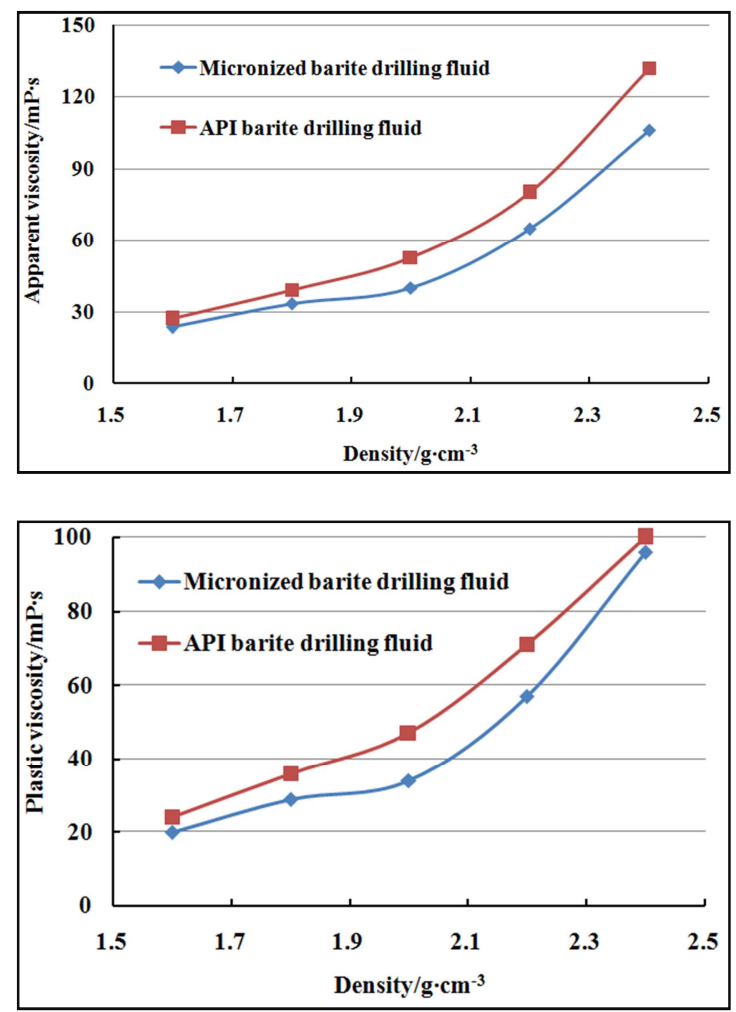

Fig. 2. The viscosity changes with the density of BF weighted with micronized barite and API barite.

Figure 1 and Figure 2 show that the viscosity of HMBF and HABF increases with the density of the drilling fluid. But at the same density, viscosity of HMBF is less than HABF. This is mainly due to the presence of polymer film on the surface of 
micronized barite after hydrophilic modification, and micronized barite particles show an elastic collision and contact. Compared with the rigid collision and contact between API barite particles, the internal friction with solid-solid phase of HMBF is reduced significantly. At the same time, the hydrophilic of micronized barite is stronger than API barite, and then the internal friction force with solid-liquid phase of HMBF is smaller. The above two aspects lead to a lower viscosity of HMBF than HABF.

\subsection{Barite Sag}

Mix the above experimental pulp fully, let stand for $24 \mathrm{~h}$, and then measure the density differences of HMBF and HABF. Experimental results are shown in Table 2. The density difference of HABF is 0.01 and $0.02 \mathrm{~g} / \mathrm{cm}^{3}$, while the density difference of HABF is much more than $0.03 \mathrm{~g} / \mathrm{cm}^{3}$. Obviously, the density difference of HMBF is lower than HABF.

As we all know, weighting materials particles are subject to electrostatic repulsion and Brownian motion effect. According to the surface electrical analysis of two kinds of barite (Figure 3 ), surface zeta potential of micronized barite is $-42.9 \mathrm{mV}$ in a solution with the $\mathrm{pH}$ value is equal to 9.58 , significantly less than that of API barite is $-28.9 \mathrm{mV}$ in an alkaline solution with the $\mathrm{pH}$ value is equal to 9.34 . Thus the electrostatic repulsion between micronized barite particles is significantly greater than API barite particles, and the particle deposition trend is also reduced.

On the other hand, Brown force has a greater influence on small particle. Based on the particle size distribution of two barites (Figure 4), the size of micronized barite $\left(D_{50}=3.656 \mu \mathrm{m}\right)$ is smaller than size of API barite $\left(D_{50}=20.08 \mu \mathrm{m}\right)$, and so that the Brown force effect on micronized barite is larger. As a result, the above-mentioned two aspects make HMBF dispersed more evenly, and its sag stability better than HABF [8].

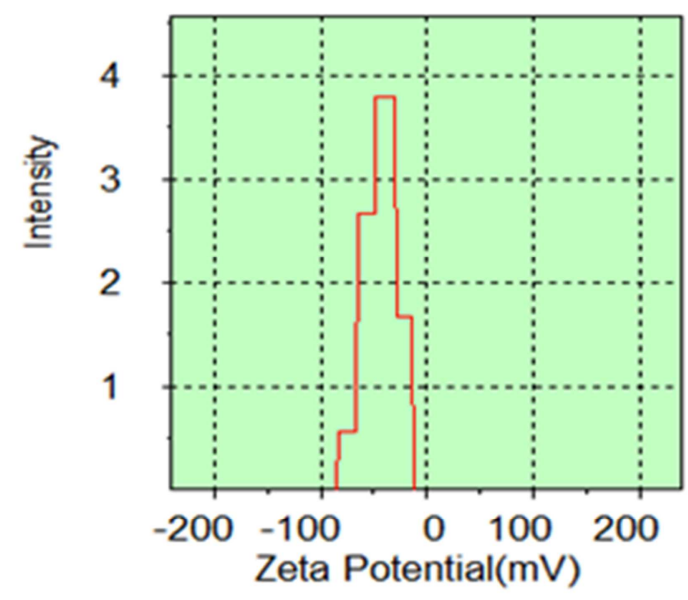

micronized barite $\zeta=-42.9 \mathrm{mv}(\mathrm{pH}=9.58)$

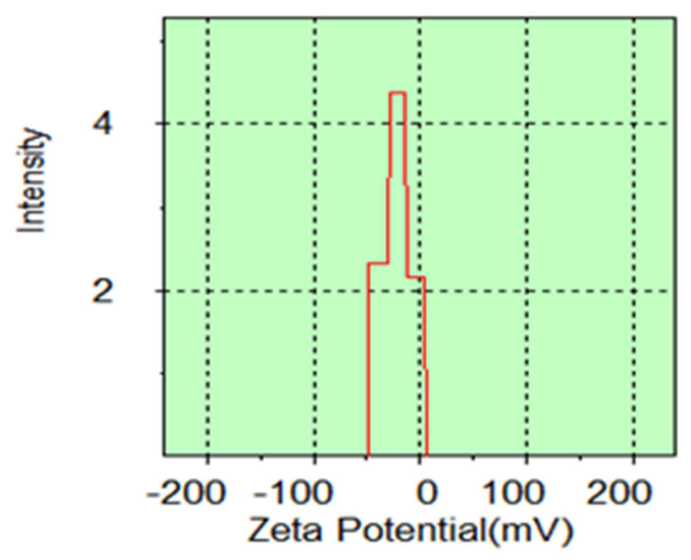

API barite $\zeta=-28.9 \mathrm{mv}(\mathrm{pH}=9.34)$

Fig. 3. Surface charge of micronized barite and API barite.

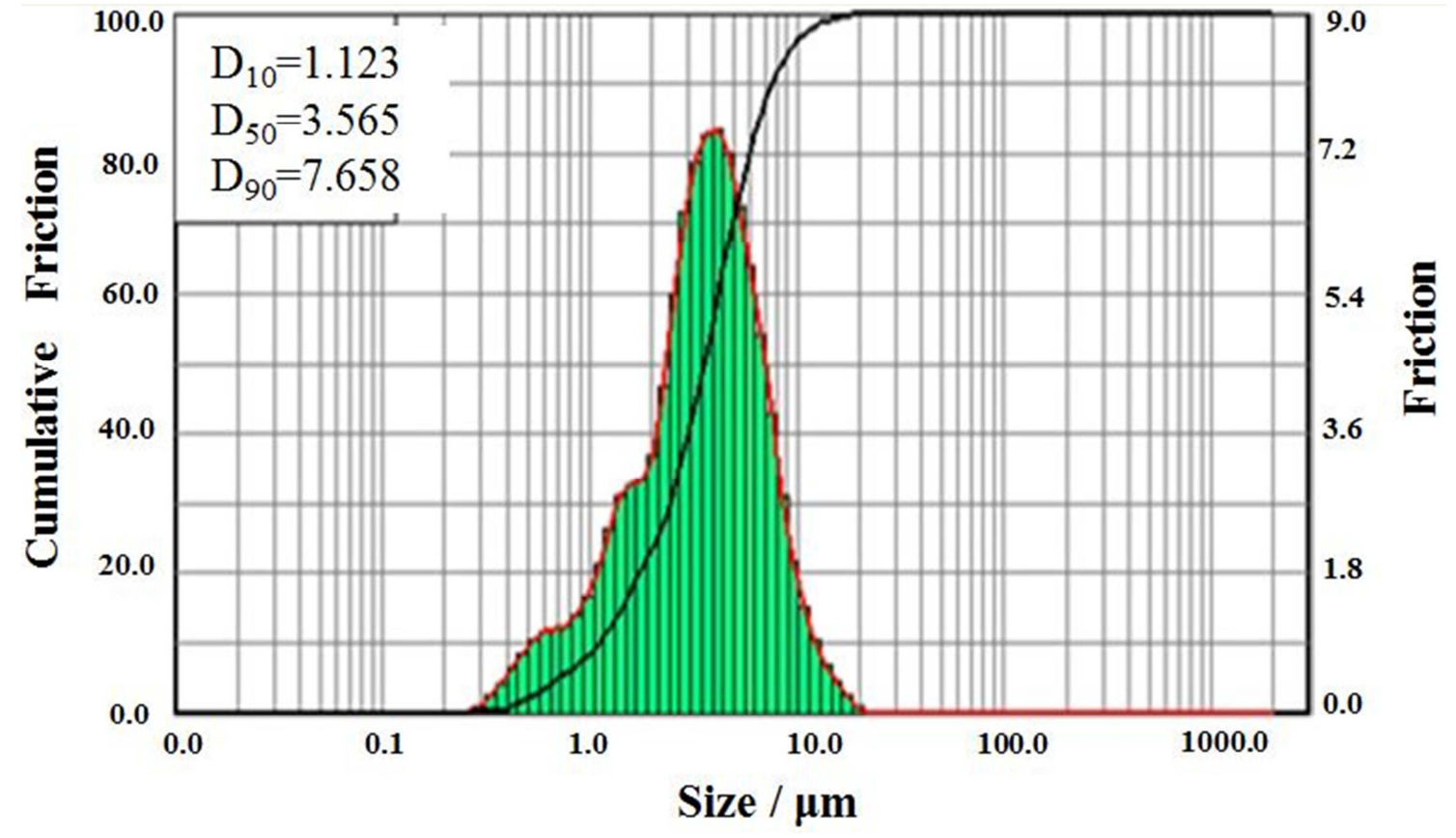




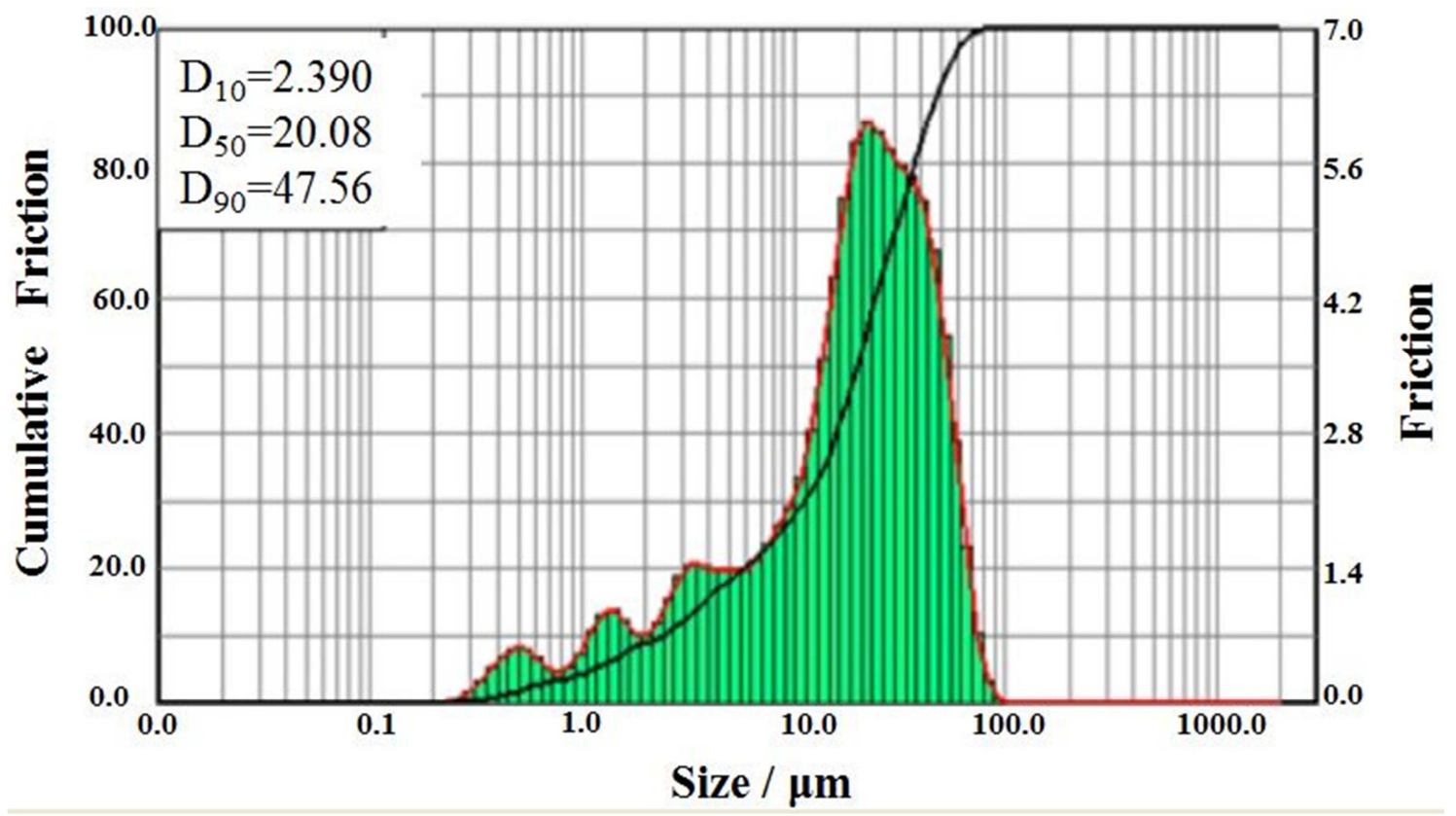

Fig. 4. PSD of micronized barite (uper) and API barite (down).

Table 2. Density difference of drilling fluids weighted with micronized barite and API barite

\begin{tabular}{lllll}
\hline \multirow{2}{*}{ Density $\mathbf{~} / \mathbf{c m}^{3}$} & \multicolumn{2}{l}{ Density difference of $\mathbf{A F ~} \mathbf{g} / \mathbf{c m}^{\mathbf{3}}$} & \multicolumn{2}{l}{ Density difference of $\mathbf{B F} \mathbf{~} / \mathbf{c m}^{\mathbf{3}}$} \\
\cline { 2 - 5 } & Micronized barite & API barite & Micronized barite & API barite \\
\hline 1.6 & 0.01 & 0.03 & 0.01 & 0.04 \\
1.8 & 0.01 & 0.04 & 0.01 & 0.04 \\
2.0 & 0.02 & 0.03 & 0.01 & 0.03 \\
2.2 & 0.01 & 0.05 & 0.01 & 0.05 \\
2.4 & 0.02 & 0.03 & 0.02 & 0.05 \\
\hline
\end{tabular}

\subsection{Lubricity}

Lubrication performance of above experimental pulp is evaluated by Extreme Pressure Lubrication Meter; and the results are shown in Figure 5. The Figure 5 shows that the lubricating coefficient of $\mathrm{HMBF}$ is around 0.110 , the minimum is 0.096 . While the lubricating coefficient of HABF is greater than 0.120 , the maximum reaches 0.138 . At the same density, lubricating coefficient of HMBF is less than mud cake friction coefficient of HABF.

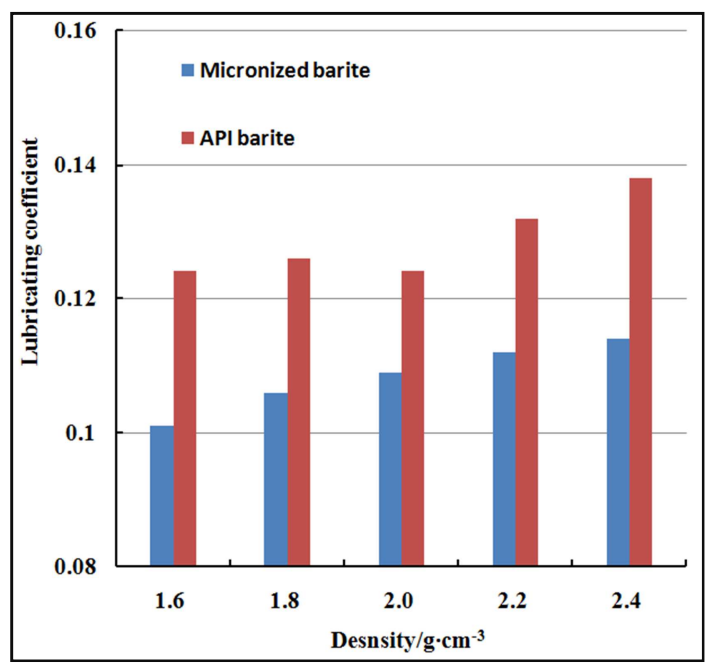

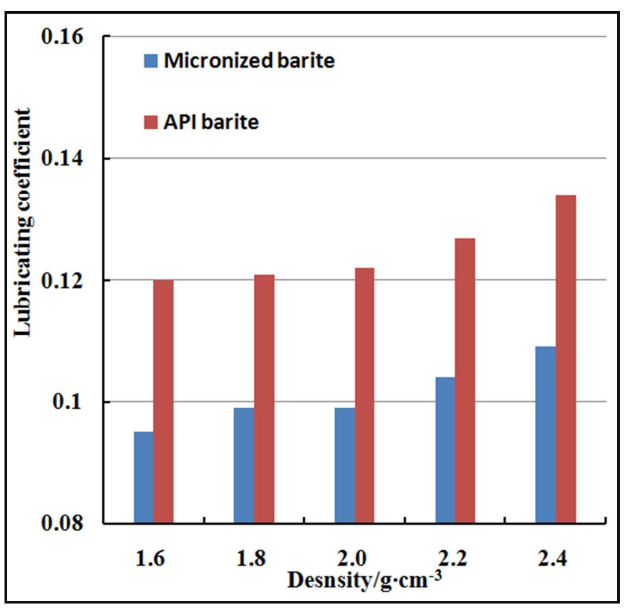

Fig. 5. Lubricating coefficient of $A F$ (left) and BF (right).

From microscopic shape (as shown in Figure 6), we know that API barite is layered structure. In the process of friction, interlayer sliding of API barite is beneficial to reducing friction. Micronized barite has small particle size. With particle size of micronized barite became smaller, than it will be approximately spherical particles and have a high degree of circularity ratio. In addition to the sliding friction between micronized barite, it also has rolling friction in the process of friction. Therefore, the lubrication performance of micronized barite is better than that of API barite. 

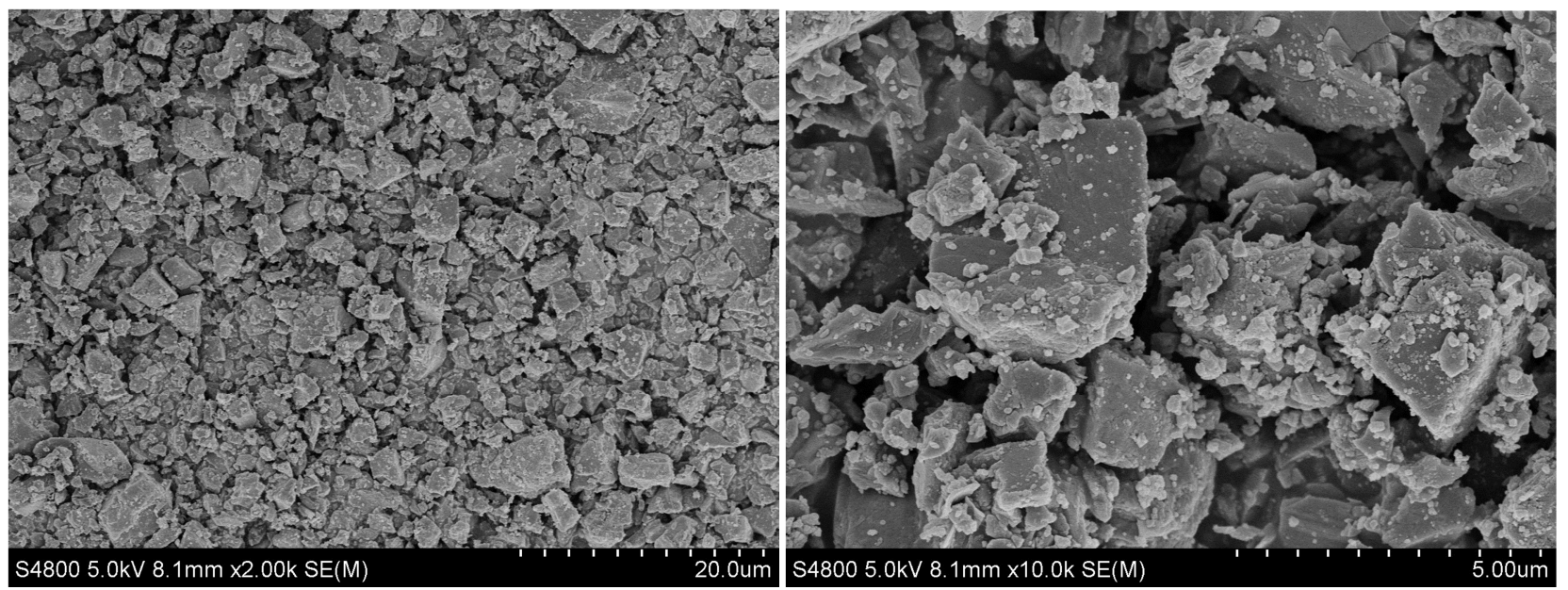

Micronized barite(left $2000 \times$, right $10000 \times$ )
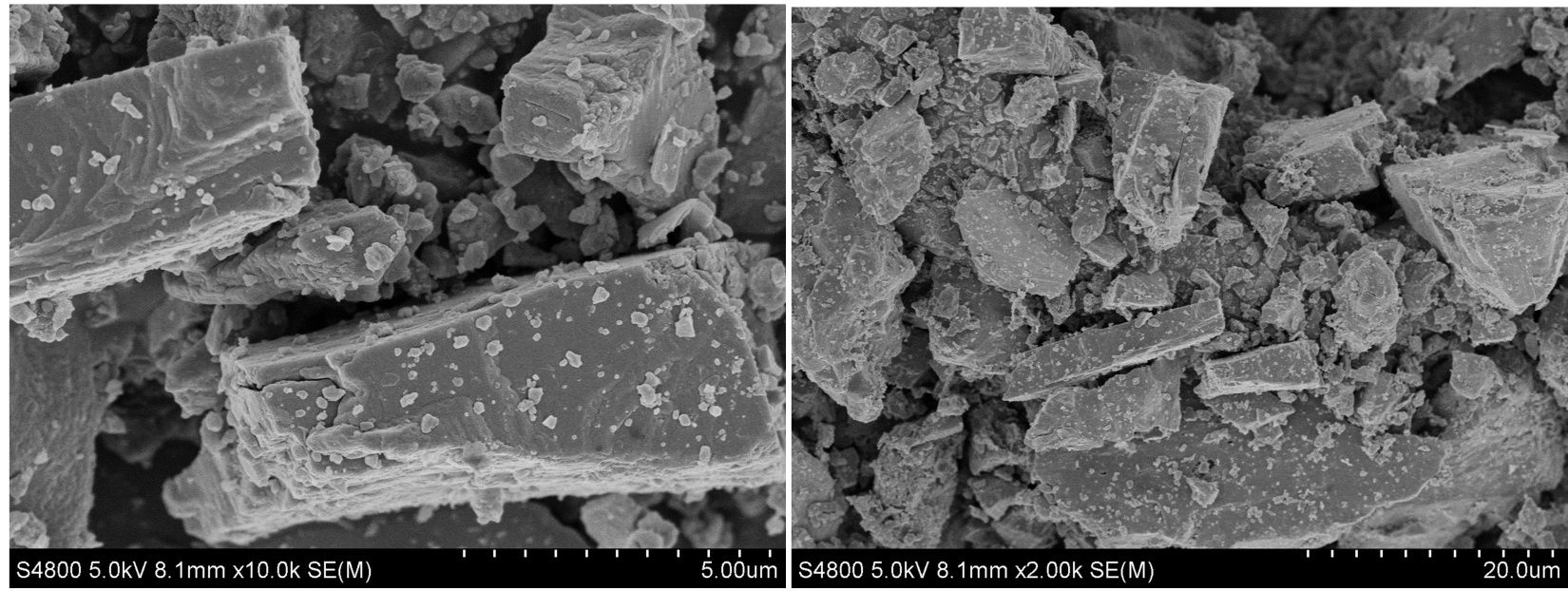

API barite (left 2000×, right10000×)

Fig. 6. SEM of micronized barite and API barite.

\section{Field Trial}

Well X-1 is the first HTHP exploration well with good gas show that was drilled successfully in offshore Western South China Sea and Well X-2 was drilled followed. Well X-1 is located in the high position of concave zone in YQ Basin Slope. The drilled strata of Well X-1 are LD Formation, YGH Formation, and HL Formation. Overlying strata of target layer is the Member 2 of YGH Formation, which is a large suite of regional mudstone, and is in sand wrapped by mud background generally. According to adjacent wells and structural layer data, pressure coefficient of target layer in Well X-1 is predicted to be 1.94-2.08, and temperature is predicted to be $182-185^{\circ} \mathrm{C}$, as shown in Figure 7 . In the actual drilling operation, formation pressure coefficient of Well X-1 is up to 2.17 and bottom hole temperature reach $187^{\circ} \mathrm{C}$ by wire-line logging.

\subsection{Challenges of Drilling Fluid}

(1) Well X-1 has a narrow safety density window of drilling fluid. Pore pressure coefficient(1.94-2.08) of target stratum is very close to fracture pressure coefficient(2.08-2.18), resulting in a small range of adjustable drilling fluid density for Well $\mathrm{X}-1$. If the density of drilling fluid is improper, it is easy to cause lost circulation when tripping in, circulating, and overflow when pulling out [9]. A double risk of well surge and leakage co-exist for Well X-1. Since the upper layer has a good gas show, drilling fluid is prone to gas cut in the drilling process of target layer, making it more difficult to maintain drilling fluid performance.

(2) HPHP puts forward higher requirements on the rheology and sag stability of the drilling fluid. High density drilling fluid should have low viscosity in HTHP condition, in order to prevent kick or lost circulation cause by surge pressure and circulating pressure increasing in the process of tripping due to high viscosity of drilling fluid. At the same time, high density drilling fluid also should have enough suspension ability, otherwise it causing barite sag and sticking [10]. 


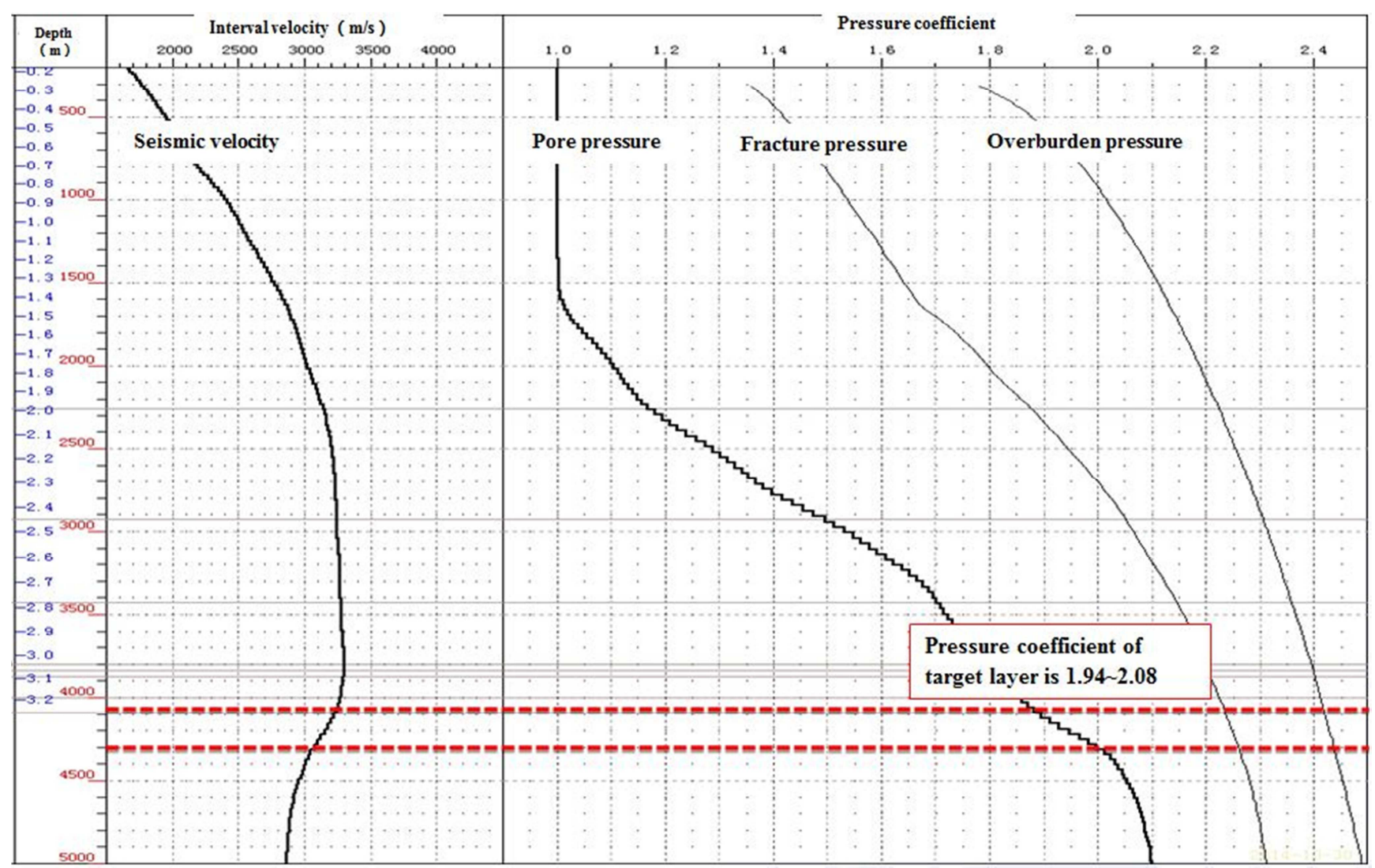

Fig. 7. Pressure curve predicted.

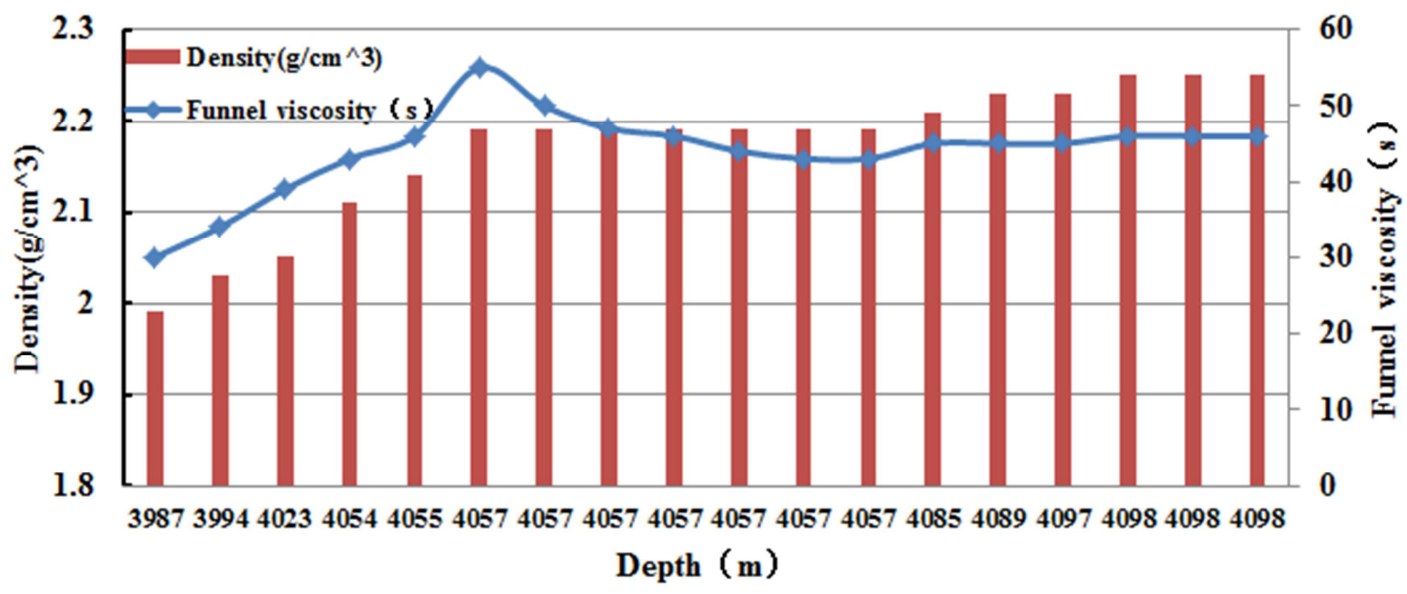

Fig. 8. Density and viscosity of drilling fluid under different depth in the field

Table 3. Properties of $H A B F$ and $H M B F$ in the flied.

\begin{tabular}{|c|c|c|c|c|}
\hline Rheology at $50^{\circ} \mathrm{C}$ & HABF@ @2.19 sg & HMBF @ $2.19 \mathrm{sg}$ & HMBF @ $2.23 \mathrm{sg}$ & HMBF @ $2.25 \mathrm{sg}$ \\
\hline Funnel viscosity(s) & 55 & 43 & 45 & 46 \\
\hline Apparent viscosity $(\mathrm{mPa} \cdot \mathrm{s})$ & 45 & 32 & 35 & 48 \\
\hline Plastic viscosity $(\mathrm{mPa} \cdot \mathrm{s})$ & 27 & 22 & 25 & 32 \\
\hline Ф6 & 17 & 20 & 18 & 23 \\
\hline$\Phi 3$ & 16 & 13 & 16 & 19 \\
\hline Yield Point(Pa) & 18 & 10 & 10 & 16 \\
\hline Gel, $10-\mathrm{s}(\mathrm{Pa})$ & 15 & 10 & 10.5 & 15 \\
\hline $\mathrm{Gel}, 10-\mathrm{min}(\mathrm{Pa})$ & 23 & 19 & 20 & 24 \\
\hline API Fluid Loss $(\mathrm{mL})$ & 3.4 & 2.4 & 1.8 & 2.4 \\
\hline HTHP Fluid Loss@150 ${ }^{\circ} \mathrm{C}(\mathrm{mL})$ & 12 & 10 & 10 & 12.8 \\
\hline
\end{tabular}




\subsection{Drilling Fluid Performance on Filed}

The field uses API barite to increase the density of drilling fluid to $2.19 \mathrm{~g} / \mathrm{cm}^{3}$ before drilling to $4057 \mathrm{~m}$. However the viscosity and yield value of API barite drilling fluid has been rising with the density increasing, as shown in Figure 8, and the amount of API barite for weighting more than the theory. When drilling to $4057 \mathrm{~m}$, with the replacement of API barite, using micronized barite to weighting the density of drilling fluid up to $2.25 \mathrm{~g} / \mathrm{cm}^{3}$. Drilling the well to $\mathrm{TD}$, the $\mathrm{HMBF}$ controls the rising trend of viscosity and yield value, and keeps the rheology stable. Table 3 is the field test of HMBF. Table 3 shows that HMBF has a low-rheology, which reducing the impact on ECD.

On the other hand, HMBF has a higher $\Phi 6 / \Phi 3$ reading of six speed viscometer. That is to say, HMBF has a lager Low Shear Rate Viscosity, which means it has good hole cleaning. When using HABF for drilling, there is a thick layer of barite at the bottom of mud pit. However there is barely obvious sag barite at the bottom of mud pit and no blockage in the pipeline while using $\mathrm{HMBF}$.

The drilling fluid is in a static state for a long time during electric logging. Due to the temperature effect, the performance of bottom hole drilling fluid with high density will vary, leading to failure logging operation easily. A few years ago, Electric logging instrument was stuck, cable broke, salvage failed, and backfill sidetracked finally in $8-3 / 8$ " hole open of adjacent Well X30-1-1A.

To ensure a successful VSP electric logging when drilling to $4057 \mathrm{~m}, \mathrm{HMBF}$ with the density of $2.21 \mathrm{~g} / \mathrm{cm}^{3}$ is padded into the open hole. There is no blocking in lowering the wireline logging tool, and no slacking off in running in drilling pipe after logging operations. Meanwhile drilling fluid has no weight variations due to sag after more than 21-hours static period. When drilling the well to $4098 \mathrm{~m}$ at TD, the electric cable is run to $4090 \mathrm{~m}$ in Grand Slam, achieving wireline logging operations in a high density of drilling. This shows that HMBF has good lubricity and sag stability.

\section{Conclusions}

Compared with API barite, micronized barite has low friction, and the contradiction between rheology and sag stability of high density drilling fluid can be addressed well by micronized barite. Micronized barite is the ideal weighing material for anti-high temperature and high density drilling fluid.

With excellent high temperature sedimentation and rheological stability, HMBF can reduce the risk of operation in offshore HTHP wells. Micronized barite has a good field application, and has good prospects for future propose.

\section{References}

[1] Zhang Yong. A study of the drilling techniques of high temperature and high pressure wells in Ying-Qiong region of South China Sea [J]. Natural Gas Industry, 1999, 19(1): 71-75.

[2] Liu Junyi, Qiu Zhengsong, Huang Weian, et al. Laboratory research on high temperature drilling and completion fluids for Dongfang Gas Field in South China Sea [J]. Petroleum Drilling techniques, 2013, 41(4): 78-82.

[3] Mahmood A, Mohammed A J. An experimental investigation of the effects of ultra-High pressure and temperature on the rheological properties of water-based drilling fluids [C]. SPE $157219,2012$.

[4] Zhao Wen, Xie Kejiang. High temperature and pressure drilling fluid technology in South China Sea [J]. Oil Drilling \& Production Technology, 2007, 29(6): 87-89.

[5] Li Yanjun, Wu Jiang, Huang Yi, et al. Key technology and application of HTHP drilling in mid-deep formations in Yinggehai Basin [J]. China Offshore Oil and Gas, 2015, 27(4): 102-106.

[6] Fimreite Gunnar, Asko Arne, Massam Jarrod, et al. Invert emulsion fluids for drilling through narrow hydraulic windows [C]. IADC/SPE 87128, 2004.

[7] Gregoire Michel, Hodder Mike, Peng Shuangjiu, et al. Successful drilling of a deviated, ultra-hthp well using a micronised barite fluid [C]. SPE/IADC 119567, 2009

[8] Qiu Zhengsong, Han Cheng, Huang Weian, et al. Research and evaluation of high-density drilling fluid weighted by micronized barite [J]. Drilling Fluid \& Completion Fluid, 2014, 31(1): $12-15$.

[9] Liu Xiaodong, Zhu Hongwei, Gao Yonghui. Drilling fluid design and test method for offshore ultra-HTHP wells and new drilling fluid technology abroad [J]. Oil Drilling \& Production Technology, 36(5): 47-52.

[10] Cai Lishan, Hu Xinzhong, Liu Sihai, et al. High density drilling fluids: bottleneck technologies and the progresses thereof [J]. Drilling Fluid \& Completion Fluid, 2007, 24(S): 38-44. 